\title{
A five-year (2016-2020) trend analysis of malaria surveillance data in Oromia regional state, Ethiopia.
}

\author{
Zalalem Olani ( $\sim$ zalalamolani8@gmail.com ) \\ Field Epidemiology Resident at Saint Pauls Millennium Medical Collage \\ Samrawit Solomon \\ Saint Pauls Millennium Medical Collage \\ Zalalem Kaba \\ East Wollega Zonal Health Department \\ Haile Bikila \\ Wollega University
}

\section{Research Article}

Keywords: Surveillance, Data analysis, Malaria, Oromia, Ethiopia

Posted Date: August 13th, 2021

DOI: https://doi.org/10.21203/rs.3.rs-789464/v1

License: (c) (i) This work is licensed under a Creative Commons Attribution 4.0 International License. Read Full License 


\section{Abstract}

Background:-Continues malaria surveillance data analysis plays a significant role in monitoring trends over time and evaluating the effectiveness of malaria prevention and control programs. Hence, this study was part of such an effort to achieve this goal. The main aim of this study was to analyses a five years (2016-2020) malaria surveillance data in Oromia region, Ethiopia.

Methods:-a descriptive cross-sectional study design was used to analyse the five years (2016-2020) trends of malaria cases in Oromia regional state, Ethiopia.

Results:-A total of 5,843,373malaria suspected cases were reported during the five-year period. Among the total reported cases 727,738 were a total of both clinical and parasitological confirmed cases. An average total malaria annual parasite incidence (API) was 4 per 1,000 person. The highest malaria cases were observed during spring and summer seasons.

Conclusions and recommendation:-Trends of total clinical and confirmed malaria cases were decreased from year to year except for the recent one year with an exceptional variability in 2019.The highest or peak of malaria cases was observed during the spring season (September-November). Malaria indicator based performance plans and achievements should be regularly and strictly reviewed and evaluated at each level.

\section{Background}

Malaria is a life-threatening protozoan disease caused by plasmodium parasites that are transmitted to people through the bites of infected female Anopheles mosquitoes. It is commonly caused by four species of the genus Plasmodium including Plasmodium vivax (PV), Plasmodium falciparum (PF), Plasmodium ovale (PO), Plasmodium malariae (PM), and Plasmodium knowlesi (PK) are known to infect human beings. Out of plasmodium species which causes malaria; $P F$ is the deadliest parasite in terms of its morbidity and mortality and the most prevalent malaria parasite in sub-Saharan Africa accounting $99 \%$ for malaria cases in 2016, whereas PV spread geographically in the most densely populated regions [1]. Globally, there were an estimated 229 million malaria cases in 2019 in 87 malaria endemic countries. Malaria deaths have reduced steadily over the period 2000-2019; from 736, 000 in 2000 to 409,000 in 2019 internationally. The global percentage of total malaria deaths among children aged less than 5 years was $84 \%$ in 2000 and $67 \%$ in 2019[2].The World Health Organization (WHO) African estimated over 200 million cases of malaria each year with $90 \%$ of cases and $90 \%$ of deaths to occur in the African[3].

In Ethiopia, $68 \%$ of the areas are endemic for malaria, and $60 \%$ of the country population are prone for infection of malaria. Mortality and morbidity attributed to malaria declined significantly from 2015/16-2018/19, though morbidity has increased in 2019/2020. Death due to malaria has declined by $67 \%$ from $0.9 / 100,000$ population to $0.3 / 100,000$ population at risk between 2016 and 2019 .Similarly, the annual parasite incidence (API) has declined by $37 \%$ from $19 / 1000$ population to $12 / 1000$ population in the same year. The number of confirmed malaria cases has reduced by $47 \%$ between 2016 and 2019. The trend of the number of malaria cases diagnosed over the last five years; in Ethiopia health sector transformation plan phase one (HSTP-I period) showed that malaria was consistently decreasing from 2016 until 2019 but it has increased in 2020. In 2020(2012 Ethiopian fiscal years); $1,509,182$ total malaria cases (clinical and laboratory confirmed) were diagnosed, among which 1,398,750 (93\%) were laboratory confirmed malaria cases. The number of total malaria cases in 2012 shows an increment by 515,183 cases (increased by $52 \%$ ) from the $2011 \mathrm{EFY}$ malaria cases. According to 2012 Ethiopian fiscal year (EFY) federal ministry of health (FMOH) annual report in Oromia regional state around $53 \%$ of total populations are at risk of malaria case, $8 \%$ incidence rate, 0.37 deaths out of 100,000 populations [4].

To realistically embark on the road towards malaria elimination, timely provision of accurate malaria surveillance data is necessary. In the context of the massive scale up of malaria interventions, there is increasing recognition that the current capacity of routine malaria surveillance, conducted in most African countries through integrated health management information systems (HMIS), is inadequate; indicators are poorly defined; data reporting and completeness are often of unknown quality; and timeliness can be extremely variable. Further, there is often limited capacity for data analysis, data interpretation, and action [5].

To create malaria-free nation, government has set a big goal of eliminating malaria by 2030[3]. To achieve the set goal, all concerned bodies in the country have shown a strong commitment. Hence, the country has been able to achieved about $50 \%$ overall malaria reduction goal by 2015 . This remarkable achievement was attained mainly due to the implementation of intensive interventional strategies such as indoor residual spraying, use of bed nets, and combination chemotherapy. However, in some endemic areas of the same country, this reduction has not yet been achieved and even it is a major cause of illness and death [5]. In the past few years, the country has achieved substantial reduction of the burden of malaria from populations at risk .Despite the above promising outcomes, Ethiopia still needs to do much for malaria elimination. And the aim of this surveillance data analysis is to provide factual information, on the trend of malaria case and locate malaria cases by place, person and time to allocate resource and act timely for elimination. Besides, the information generated from the analysis of surveillance data is important to initiate public health action, helps to identify the available gaps in the surveillance system.

Figure 1:-Overview of data source, flow and use in malaria M\&E system (adapted from National Malaria Program Monitoring and Evaluation Plan 20142020).

\section{Methods And Materials}




\subsection{Study area and period}

It was conducted in Oromia Regional State, Ethiopia. It is one of the ten regions in Ethiopia. Addis Ababa is the capital city of the region. Currently, it consist 21 administrative Zones and 19 towns. The region is bordered by the Somali Region to the east; the Amhara Region, the Afar Region and the Benishangul-Gumuz Region to the north; Dire Dawa to the northeast; the South Sudanese state of Upper Nile, Gambella Region, Southern Nations, Nationalities, and Peoples' Region and Sidama Region to the west; the Eastern Province of Kenya to the south; as well as Addis Ababa as an enclave surrounded by Oromia Special Zone Surrounding Finfinne in its centre and the Harari Region as an enclave surrounded by East Harerghe in its east. Malaria surveillance data or Oromia region reported on a weekly or monthly or yearly basis for the last five years (2016-2020) was analysed and interpreted from March 22-May 15, 2021.

Figure 2:- Map of Oromia Regional State, Ethiopia, May 2021.

\subsection{Study Design}

- A descriptive cross-sectional study design was employed to assess a five-year (2016-2020) trend analysis of malaria surveillance data in Oromia regional state, Ethiopia.

\subsection{Population}

\subsubsection{Source population}

- The source population were any people living in Oromia region that have been sought health care services within the Oromia regional state from January 2016-December 2020.

\subsubsection{Study Population}

- All reported cases of malaria in Oromia region health facilities between January 2016 and December 2020 who fulfils inclusion criteria.

\subsection{Inclusion and Exclusion criteria}

- A total of five-year period confirmed and clinically treated cases for malaria were included in the study, and all incomplete data were excluded.

\subsection{Study Variables}

- Months

- Zone

- Confirmed and clinical malaria case

- Suspected fever cases examined for malaria case

- Confirmed case PF malaria cases

- Confirmed case PV malaria cases

- Inpatient case due to malaria

- Inpatient death due to malaria

- Clinical malaria case

\subsection{Data collection tools and procedures}

Five-year secondary data were obtained from Ethiopian public health institute (EPHI) PHEM weekly surveillance data of 2016-2019. Variables such as Zones, Woreda, clinical and confirmed, inpatient, outpatient, PF and PV, malaria suspected cases and malaria deaths were included in the data base.

\subsection{Data processing and Analysis}

All data were checked for completeness and cleaned for any inconsistencies to analyse. The data were entered and analysed with Microsoft office Excel 2010. Descriptive statistics were used to show the trends of malaria transmission in terms of seasons, years and species of malaria parasite. The analysed data were presented using tables and figures.

\subsection{Data Quality Control}

The collected data were checked for completeness, accuracy, clarity and consistency throughout the data collection period in order to maintain the quality of data.

\subsection{Ethical Considerations}


Ethical clearance was secured by writing formal letter from St. Paul's hospital millennium medical college (SPHMMC) to Ethiopian public health institute (EPHI) and then submitted to public health emergency management (PHEM) surveillance team. Official permission was obtained from concerned authorities of the health office. The surveillance officers and other health professionals were informed about the objective and purpose of the surveillance data analysis in order to cooperate with data analyser throughout data collection and analysis.

\subsection{Operational definitions}

- Suspected malaria case:-Clinical diagnosis of malaria is made in a patient who has fever or history of fever in the last 48 hour and lives in malariaendemic areas or has a history of travel within the last 30 days to malaria endemic areas.

- Confirmed malaria case:-A suspected case of malaria in which malaria parasites have been verified by microscopy or RDT(rapid diagnostic test)

- Annual parasite incidence:-Total number of positive slides for malaria parasite in a year *1000/population at risk.

- Malaria outbreaks:-Crossing the norm line or doubling the number of malaria cases compared to the prior year of reported WHO epidemic week.

- Slide positivity rate/SPR:-The number of laboratory confirmed malaria case per 100 cases examined cases.

\section{Results}

Oromia regional state five-year (2016-2020) malaria surveillance data was systematically analysed and verified. It indicated that, the total of 5,843,373 malaria suspected cases were reported in the region from January 2016 - December 2020. Among the reported cases, 727,738(clinically confirmed cases:-15,655, 2.2\%, and parasitological confirmed cases:-712,083, 97.8\%). Malaria detection rate from total suspected fever examined by RDT or microscopy and clinical case were, $12 \%(712,083 / 5,843,373 * 100)$. During the study period (2016-2020); API were decreased by 5.3 per 1,000, and 3.8 per 1,000 and 2.4 per 1,000 during 2016, and 2018 respectively. Conversely, it showed an increment during 2019 by 4 and slight decrement by 3.7 in 2020 s. Among the parasitological confirmed cases; PF constitutes $68.2 \%(485,350 / 712,083 * 100)$ while the rest $31.8(226,733 / 712,083 * 100)$ were covered by $P V$ [Table 1, Fig. 3].

\subsection{Description of Malaria Morbidity and Mortality by Time}

Table 1

Last five-years summarized malaria reported data from January 2016-December 2020 of Oromia Regional State, Ethiopia.

\begin{tabular}{|c|c|c|c|c|c|}
\hline \multirow[t]{2}{*}{ Years } & \multirow{2}{*}{$\begin{array}{l}\text { Total } \\
\text { population(population } \\
\text { at risk) }\end{array}$} & \multirow{2}{*}{$\begin{array}{l}\text { Total } \\
\text { malaria suspected } \\
\text { fever examined }\end{array}$} & \multirow[t]{2}{*}{$\begin{array}{l}\text { Total malaria parasitological confirmed and } \\
\text { clinical(that is both } P F \text { and } P V \text { ) }\end{array}$} & \multicolumn{2}{|c|}{$\begin{array}{l}\text { Total positive malaria by RDT or } \\
\text { microscopy Outpatient Cases }\end{array}$} \\
\hline & & & & PF & PV \\
\hline 2016 & $34,895,497$ & 1252144 & 196451 & 116740 & 70919 \\
\hline 2017 & $35,856,743$ & 1152288 & 140526 & 90045 & 47196 \\
\hline 2018 & $36,839,051$ & 1099258 & 92129 & 60979 & 30325 \\
\hline 2019 & $37,831,920$ & 1244753 & 151319 & 111607 & 38308 \\
\hline 2020 & $38,865,436$ & 1094930 & 147313 & 105979 & 39985 \\
\hline \multicolumn{2}{|c|}{ Grand Total } & $5,843,373$ & 727,738 & 485,350 & 226,733 \\
\hline
\end{tabular}

Figure 3:-Trends of API from January 2016-December 2020, Oromia Regional State, Ethiopia.

From a total cases of malaria reported during study period; those cases confirmed by microscopy or RDT were increasing from $95.5 \%$ in 2016 to $97.6 \%$ in 2017 and then slightly constant from 2019 to 2020 by $99 \%$ [Figure 4].

Figure 4:-Trends of confirmed malaria cases in percentage from 2016-2020, Oromia regional state, Ethiopia.

\subsection{Trends of Malaria case by species}

Regarding the identified plasmodium species, both species of plasmodium were reported in each year with $P F$ being the predominant species in the study area. From the total of 712,083 outpatient confirmed cases reported during the five-year $(2016-2020), 68.2 \%(485,350)$ of the case were due to $P F$, and the rest 22,673(31.8\%) were due to $P V$. PF and $P V$ were the only species in study area, where $P F$ accounted for (68.2\%) of the overall incidence, followed by $P V$ constituting (31.8\%). The incidence of $P F$ cases was decreasing beginning from (2016-2018) by 3.3 per 1,000, 2.5 per 1,000 and 1.7 per 1,000 persons and by the year 2019 shows a slight increment by 3 per 1,000 and by 2020 year it shows a slight decrement 2.7 per 1000 person respectively. The incidence of $P V$ was 2 per 1,000, 1.3 per 1,000 and 0.8 per 1,000 person in (2016-2018) and from (2019-2020) the case showed relatively constant by 1 per 1,000, and 1 per 1,000 person. In the past five-year trend, $P F$ was more dominant over $P V$ [Figure 5].

Figure 5:-Trends of positive malaria cases with species from 2016-2020, Oromia, Ethiopia. 
Even though malaria case occurred in all seasons, the incidence had fluctuating trend across four seasons over the last five-years. The highest malaria cases were observed during two seasons; the first one was in spring by 249,902 (35\%) and the second one was in summer by 205,477 ( $28.8 \%$ ). On the other hand the lowest cases were observed during winter by $125,001(17.5 \%)$. With regards to the species, higher number of cases of $P F$ and $P V$ were observed during Spring 177,787(36.6\%), 72,115(30.1\%), and Summer 142,845 (29.7\%), 62,632 (27.6\%) respectively. However, the minimum numbers of $P F$ $78,424(16 \%)$ in spring, and slightly decrement of $P V$ cases by $45,409(20.1 \%)$ were observed during autumn [Figure 6].

Figure 6:-The distribution of PF and PV species in different seasons from 2016-2020, Oromia Regional State, Ethiopia.

The peak weekly incidence rate in the past five years was observed on week 41 of 2020 with 166 cases per 100,000 population and the lowest weekly incidence rate was reached on week 5 of 2018 with 19 cases per 100,000 population[Figure 7].

Figure 7:-Trends of malaria in WHO Epidemic Weeks from January 2016-December 2020, Oromia Regional State, Ethiopia.

From a total of 727,738 suspected fever cases examined by RDT or Microscopy, 712,083 patients were positive for plasmodium species from January 2016 to December 2020 , and then an average malaria slide positivity rate (SPR) of $96 \%$. Malaria SPR was increased from 2016 to 2018 by $96 \%, 98 \%$, $99 \%$, respectively and kept constant in 2019 and 2020 by $99 \%$ [Figure 8].

Figure 8:-Trends of malaria SPR from January 2016-December 2020, Oromia Regional State, Ethiopia.

\subsection{Malaria Morbidity and Mortality by place}

PF was the most commonly reported species accounted for $485,350(68 \%)$ of the cases while $P V$ was reported among 226,733 (32\%) of the positive results. Among all Zones and towns of Oromia region, $P F$ is the highest in magnitude in 19 Zones and towns and $P V$ is highest in 18 Zones and towns of Oromia region. The magnitude of the species was different among Zones and towns of the region [Table 2]. 
Table 2

Malaria cases distribution by species by from January 2016- December 2020 in Zones and towns, of Oromia Regional State, Ethiopia.

\begin{tabular}{|c|c|c|c|c|c|c|}
\hline \multirow[t]{2}{*}{ S.no } & \multirow{2}{*}{$\begin{array}{l}\text { Lists of Zones and towns in the } \\
\text { region }\end{array}$} & \multirow{2}{*}{$\begin{array}{l}\text { Total parasitological confirmed } \\
\text { case }\end{array}$} & \multicolumn{2}{|c|}{ Total five years PF } & \multicolumn{2}{|c|}{ Total Five years PV } \\
\hline & & & Frequency $(\mathrm{N})$ & $\begin{array}{l}\text { Percentage } \\
(\%)\end{array}$ & Frequency $(\mathrm{N})$ & $\begin{array}{l}\text { Percentage } \\
(\%)\end{array}$ \\
\hline 1 & Adama Special town & 5545 & 2167 & 39 & 3378 & 61 \\
\hline 2 & Ambo town & 154 & 60 & 39 & 94 & 61 \\
\hline 3 & Arsi & 20642 & 13070 & 63 & 7572 & 37 \\
\hline 4 & Assela town & 425 & 86 & 20 & 339 & 80 \\
\hline 5 & Bale & 2086 & 1794 & 86 & 292 & 14 \\
\hline 6 & Bishoftu town & 2916 & 822 & 28 & 2094 & 72 \\
\hline 7 & Borena & 36336 & 28813 & 79 & 7523 & 21 \\
\hline 8 & Buno Bedele & 14971 & 11998 & 80 & 2973 & 20 \\
\hline 9 & Burayu town & 279 & 70 & 25 & 209 & 75 \\
\hline 10 & Dukem town & 930 & 384 & 41 & 546 & 59 \\
\hline 11 & East Hararge & 41213 & 36214 & 88 & 4999 & 12 \\
\hline 12 & East Shewa & 98223 & 59751 & 61 & 38472 & 39 \\
\hline 13 & East Wollega & 51698 & 39597 & 77 & 12101 & 23 \\
\hline 14 & Finfine Zuria & 3545 & 1872 & 53 & 1673 & 47 \\
\hline 15 & Gelan town & 83 & 18 & 22 & 65 & 78 \\
\hline 16 & Guji & 29240 & 21196 & 72 & 8044 & 28 \\
\hline 17 & Holeta town & 106 & 42 & 40 & 64 & 60 \\
\hline 18 & Horo Gudru Wollega & 33591 & 21386 & 64 & 12205 & 36 \\
\hline 19 & Ilu Aba Bora & 19521 & 12842 & 66 & 6679 & 34 \\
\hline 20 & Jimma & 32566 & 21364 & 66 & 11202 & 34 \\
\hline 21 & Jimma Special town & 4785 & 1189 & 25 & 3596 & 75 \\
\hline 22 & LegeDadi LegeTafo town & 156 & 54 & 35 & 102 & 65 \\
\hline 23 & Modjo town & 1514 & 663 & 44 & 851 & 56 \\
\hline 24 & Nekemte town & 2234 & 989 & 44 & 1245 & 56 \\
\hline 25 & North Shewa & 11511 & 7841 & 68 & 3670 & 32 \\
\hline 26 & Kelem Wollega & 44744 & 30125 & 67 & 14619 & 33 \\
\hline 27 & Robe town & 1 & 1 & 100 & 0 & 0 \\
\hline 28 & Sebeta town & 1605 & 372 & 23 & 1233 & 77 \\
\hline 29 & Shashamane town & 10480 & 3308 & 32 & 7172 & 68 \\
\hline 30 & South West Shewa & 22799 & 10608 & 47 & 12191 & 53 \\
\hline 31 & Sululta town & 66 & 16 & 24 & 50 & 76 \\
\hline 32 & West Arsi & 19023 & 10044 & 53 & 8979 & 47 \\
\hline 33 & West Guji & 58376 & 40653 & 70 & 17723 & 30 \\
\hline 34 & West Hararge & 9110 & 8032 & 88 & 1078 & 12 \\
\hline 35 & West Shewa & 44946 & 26796 & 60 & 18150 & 40 \\
\hline 36 & West Wollega & 83646 & 70668 & 84 & 12978 & 16 \\
\hline 37 & Woliso town & 3017 & 445 & 15 & 2572 & 85 \\
\hline Granc & Total & 712,083 & 485,350 & 68 & 22,6733 & 32 \\
\hline
\end{tabular}


East Shoa recorded the highest total confirmed malaria case with 98,223,West Wollega, West Guji, East Wollega, West Shoa ,Kellem Wollega, East Hararge, Borena, HorroGuduru Wollega, and Jimma are have recorded the respective rank next to East Shoa[Figure 9].

Figure 9:- Top ten Zones of Oromia regional state by total confirmed malaria cases from January 2016-December 2020, Ethiopia.

More malaria deaths were observed by the analysis of past five-years in Oromia regional state. West Arsi, West Wollega, West Hararge and Kellem Wollega Zones had more number of deaths respectively than the others Zones[Table 3].

Table 3

-Total malaria deaths by Zones and towns of Oromia Regional State from January 2016-December 2020, Ethiopia.

\begin{tabular}{|ll|}
\hline Zone and towns & Total number of malaria death within the last five-years(2016-2020) \\
\hline West Arsi & 20 \\
\hline West Wollega & 13 \\
\hline West Hararge & 9 \\
\hline Kelem Wollega & 7 \\
\hline HoroGudru Wollega & 4 \\
\hline Ilu Aba Bora & 4 \\
\hline West Guji & 3 \\
\hline Finfine Zuria & 1 \\
\hline East Wollega & 1 \\
\hline West Shewa & 1 \\
\hline Other Zones or towns in Oromia region & 0 \\
\hline Grand Total & 63 \\
\hline
\end{tabular}

A total of 5,180 malaria inpatient cases and 63 deaths were reported for the last five-years from January 2016-December 2020.The case fatality rate (CFR) was high in (2018) with $5.9 \%$. CFR showed consistent increment from $2016-2018$, by $0.4 \%$, $0.8 \%$, and $5.9 \%$ respectively. It was $1.2 \%, 1.6 \%$ during 2019 and 2020 respectively [Figure 10].

Figure 10:-Trends of malaria CFR in Oromia regional state from 2016-2020, Ethiopia.

\section{Discussion}

The present study attempted to assess the trend of malaria incidence in Oromia regional state from January 2016-December 2020, Ethiopia. According to the last five-years malaria surveillance data of Oromia regional state, a total of malaria cases by Zone indicated that high number of cases was found in East Shoa, West Wollega, West Guji, East Wollega, Kellem Wollega, East Hararge, Borena, Horo Guduru Wollegga and Jimma. Besides,more malaria deaths were observed in West Arsi, West Wollega, West Hararge, Kellem Wollega, Horro Guduru Wollega, llu Aba Bora, West Guji, Finfinne zuria, East Wollega and West Shoa respectively.

Trends of total clinical and confirmed malaria cases were decreased from year to year except for the recent one year with an exceptional variability in 2019. The highest or peak of malaria cases was observed during the spring season (September-November). In this assessment, a total of 727,738 confirmed and clinical malaria cases were reported within the last five-year period from January 2016-December 2020 with mean annual occurrence of 145,548 cases. It could be an important indicator for existence of malaria burden in the study area, which seems to need due attention with regard to malaria intervention during this critical period of the national striving towards malaria elimination in the year 2030[6].

The general declined number of clinical malaria cases was seen in the study (2.15\%). The same study conducted in Azebo northern Ethiopia from 20112016 indicated that the decline in the number of clinical malaria cases [7]. Another study done in Oromia regional state, Batu town from 2012-2017 indicated that there is huge decline in the number of clinical cases [8]. This may be due to improved provision of diagnostic facilities like RDT and diagnostic microscope for health facilities.

$P F$ and $P V$ were the dominant cause of malaria in Oromia regional state from $2016-2020$ accounting for $68.2 \%$ and $31.8 \%$ respectively. $P F$ is the most prevalent malaria parasite in the WHO African Region, accounting for $99.7 \%$ of estimated malaria cases in 2018, as well as in the WHO South-East Asia Region (50\%), the WHO Eastern Mediterranean Region (71\%) and the WHO Western Pacific Region (65\%)[5]. This assessment was in line with the study conducted in Ethiopia during 2016, which revealed that, $P F$ is the leading cause of malaria in Ethiopia by $60 \%$ while $P V$ causes $40 \%$ of malaria in Ethiopia [9]. A five-year trend analysis of malaria prevalence in Dembecha health center, West Gojjam Zone, northwest Ethiopia 2016 indicated the same condition for the causative agents of malaria which is, $P F$ cause about $68.2 \%, P V$ causes $26.3 \%[8]$. 
Unlikely to our study result shows a difference on proportions of the species compared to other studies; "Malaria epidemiology and interventions in Ethiopia from 2001 to 2016", shows PF and PV co-exists, accounting for 60 and 40\% of all malaria cases, respectively[11]. Another study done in "Oromia regional state, in Adama City" out of 6862 malaria cases reported from OPD data from 2013/14 to 2017/18 in retrospective study, $61 \%$ was $P V$ and $39 \%$ was $P F[12]$.

In this assessment, malaria cases were reported in all of the four seasons of Ethiopia. The peak of malaria incidence occurs during spring season (September, October and November) and the second peak of malaria incidence was observed during summer season (June, July, August). This finding was in line with the studies conducted in Bale Zone, North West Tigray, East Wollega Zone, and Wolkite health center $[13,10,8,6]$.

API was decreased by 5.3 per 1000, 3.8 per 1000 and 2.4 per 1000 during 2016, and 2018 respectively. Conversely, it showed an increment during 2019 by 4 and slight decrement by 3.7 in 2020 s per 1000 population respectively. In 2020, the FMOH updated the country's malaria risk strata based upon malaria $\mathrm{API}$ is that; areas with malaria transmission risk by (<= 5 cases $/ 1,000$ population/year) is classified as very low API, so Oromia regional state is categorized under low risk classification according to $\mathrm{FMOH}[3]$. Proportion of parasitological confirmation treatment rate was sharply increases from (95.5\%) to (99\%) during the last five-years (2016-2020) respectively. Unlikely, the clinical malaria treatment rate was decreases in the same study year from $(4.5 \%)$ to $(0.99 \%)$.This retrospective study was unlike with a five-year trend analysis of malaria prevalence in Mankush health center, Guba district, Benishangul- Gumuz regional state, and western Ethiopia from 2014-2018;which shows dramatic decrement of parasitological confirmation treatment rate from $85 \%-51 \%[14]$. This controversial issue might be due to improper supply of diagnostic materials, lack of well-trained health professionals on the diagnostic materials.

A total of 5,180 malaria inpatient cases and 63 deaths were reported for the last five-years (January 2016-December 2020). The CFR in the same period was fluctuating. It was high in (2018) with $5.9 \%$. CFR showed consistent increment from $2016-2018$, by $0.4 \%, 0.8 \%$, and $5.9 \%$ respectively. It was $1.2 \%$, $1.6 \%$ during 2019 and 2020 respectively. This was in agreement with the study done in Bale zone from 2010-2017 also support our findings which describes that annual number of malaria death is fluctuating by $0 \%, 1 \%, 2 \%$ in 2010,2011 and 2012 respectively and $0 \%$ from $2013-2016$ and $6 \%$ in $2017[15]$.

\section{Limitations of the study}

The data we analysed lacks important personal variables such as age, sex, pregnancy status of females, due to this fact it is difficult to analyse the impact of malaria by age and sex.

\section{Conclusion And Recommendation}

\subsection{Conclusion}

Trends of total clinical and confirmed malaria cases were decreased from year to year except for the recent one year; with an exceptional variability in 2019. The highest peak of malaria cases was observed during the spring season(September-November). The highest cases were seen in East Shoa,West Wollega, West Guji, East Wollega, Kellem Wollega, East Hararge, Borena, Horo Guduru Wollega and Jimma. Malaria related death happened within the study period in the following zones of Oromia regional state:- West Arsi, West Wollega, West Hararge, Kellem Wollega, Horroguduru,Wollega, llu Aba Bora, West Guji, Finfinne zuria, East Wollega and West Shewa. Malaria is an important public health problem in the study area with a predominance of $P F$ and $P V$ infection. It could be an important indicator for existence of malaria burden in the study area, which seems to need due attention with regard to malaria intervention during this critical period of the national striving towards malaria elimination in the year 2030.

\subsection{Recommendation}

Depending on our assessment results, we would like to forward the following recommendations to EPHI, Oromia Regional Health Bureau(ORHB), SPMMC and other concerned bodies or stakeholders:-

- Strong emphasis should be given to malaria surveillance data analysis and use for decision making at country level as well as regional level, with an effort to avert higher cases of malaria in the study area, performance plans and achievements should be regularly and strictly reviewed and evaluated at each level.

- Zones with highest cases like East Shoa,West Wollega, West Guji, East Wollega, Kellem Wollega, East Hararge, Borena, Horo Guduru Wollega and Jimma should be given special attention.

- Zones with malaria related deaths like West Arsi, West Wollega, West Hararge, Kellem Wollega, Horroguduru Wollega,llu Aba Bora, West Guji, Finfinne zuria, East Wollega and West Shoa requires special intervention.

- We recommend the Zonal and Woreda health offices, health workers, health extension workers, and the community to strength early detection and treatment of malaria cases at all level to decrease malaria inpatient and CFR which is part of strengthening surveillance data analysis.

- The Regional health bureau and the district health office should plan to do further study to know the cause of high incidence of $P F$ malaria species, malaria inpatient and malaria CFR for prevention and control of malaria to come to elimination.

- It is better if personal variables such as age, sex and pregnancy are incorporated in PHEM reporting format for detail analysis of the impact of malaria on personal characteristics and to identify the risk groups. 
- The PHEM officers at district and health facility level should strength documentation and handling of malaria data by species in all kebele of the district and analyse the data and alert the community before occurrence of outbreak during pick transition seasons.

\section{Declarations}

\section{Acknowledgements}

We are grateful to academicians and experts from EPHI and St. Paul Hospital Millennium Medical College Faculty of Public Health for their valuable contribution during the assessment.

\section{Ethics approval and consent to participate}

Ethical clearance was secured by writing formal letter from St. Paul's hospital millennium medical college (SPHMMC) to Ethiopian public health institute $(\mathrm{EPHI})$ and then submitted to public health emergency management (PHEM) surveillance team. Official permission was obtained from concerned authorities of the health office. The surveillance officers and other health professionals were informed about the objective and purpose of the surveillance data analysis in order to cooperate with data analyser throughout data collection and analysis.

\section{Consent for publication}

'Not applicable'

\section{Availability of data and materials}

The finding of this study was generated from the data collected and analyzed based on stated methods and materials. The original data supporting this finding are available from the corresponding author on reasonable request.

\section{Competing interests}

"The authors declare that they have no competing interests"

\section{Funding}

'Not applicable'

\section{Authors' contributions}

ZO participated in the design of the study, performed the data collection and the statistical analysis and served as the corresponding author of the manuscript. SS, ZK and HB supervised the study, ensured quality of the data, assisted in the analysis and interpretation of the data. All authors read and approved the manuscript.

\section{Authors' information}

- ZO is Field Epidemiology Resident at Saint Pauls Millennium Medical Collage, Department Of Public Health, Addis Ababa, Ethiopia.

- SS is lecturer at Saint Pauls Millennium Medical Collage department of Public Health, Institute of Health Sciences, Addis Ababa, Ethiopia.

- ZK is Water, Sanitation, Hygiene (WASH) and Neglected Tropical Diseases (NTDs) Program Coordinator, Nekemte town, Western Ethiopia.

- HB is Lecturer at Wollega University department of Public Health, Institute of Health Science, Nekemte, Western Ethiopia.

\section{Abbreviations}

- API:-Annual Parasitic Incidence

- CFR:-Case fatality rate

- CSA:-Central statistical Agency

- EPHI:-Ethiopian Public Health Institute

- FMOH:-Federal Ministry of Health

- ORHB:-Oromia Regional Health Bureau 
- PF:-Plasmodium Falciparum

- PHEM:-Public Health Emergency Management

- PV:-Plasmodium vivax

- RDT:-Rapid Diagnostic Test

- SPMMC:-Saint Paul Millennium Medical Collage

- SPR-Slide positivity rate

- WHO:-World Health Organization

\section{References}

1. World malaria report, 2018.

2. Report WM. World malaria report, 2020.

3. MOH. Ethiopia malaria elimination strategic plan: 2021-2025. 2021;(August 2020):2021-5.

4. Report P. Performance report 2012. 2020.

5. FMOH. National Malaria Guidelines, Fourth edition. 2017;(November):1-108. Available from: https://www.humanitarianresponse.info/sites/www.humanitarianresponse.info/files/documents/files/eth_national_malaria_guidline_4th_edition.pdf.

6. Solomon A, Kahase D, Alemayehu M. Trend of malaria prevalence in Wolkite health center: an implication towards the elimination of malaria in Ethiopia by 2030. Malar J [Internet]. 2020;1-8. Available from: https://doi.org/10.1186/s12936-020-03182-z.

7. Tesfay K, Yohannes M, Bayisa S. Trend analysis of malaria prevalence in Raya Azebo district, Northern Ethiopia : a retrospective study. BMC Res Notes [Internet]. 2018;1-5. Available from: https://doi.org/10.1186/s13104-018-4003-4.

8. Hassen J, Dinka H. Retrospective analysis of urban malaria cases due to Plasmodium falciparum and Plasmodium vivax: the case of Batu town, Oromia, Ethiopia. Heliyon [Internet]. 2020;6(3):e03616. Available from: https://doi.org/10.1016/j.heliyon.2020.e03616.

9. Box PO. Current Status of Malaria in Ethiopia: Evaluation of the Burden, Factors for Transmission and Prevention Methods. 2018;7(1):1-6.

10. Haile D, Ferede A, Kassie B, Abebaw A, Million Y. Five-year trend analysis of malaria prevalence in Dembecha health center, west gojjam zone, northwest Ethiopia: A retrospective study. J Parasitol Res. 2020;2020.

11. Taffese HS, Hemming-Schroeder E, Koepfli C, Tesfaye G, Lee MC, Kazura J et al. Malaria epidemiology and interventions in Ethiopia. No Title. Infect Dis poverty. 2018;1-9.

12. File T, Dinka H GL. No TitleA retrospective analysis on the transmission of Plasmodium falciparum and Plasmodium vivax. The case of Adama town.Ethiopia. Malar J. 2019;[Internet].

13. Falaho Sani Kalil, Mohammed Hasen Bedaso, Shukri Kabeta Wario. Trends of Malaria Morbidity and Mortality from 2010 to 2017 in Bale Zone, Ethiopia: Analysis of Surveillance Data. Infection and Drug Resistance 2020:13.

14. Alkadir S, Gelana T, Gebresilassie A. A five year trend analysis of malaria prevalence in Guba district, Benishangul- Gumuz regional state, western Ethiopia : a retrospective study. 2020;4:1-7.

15. Sani Kalil F, Hasen Bedaso M, Kabeta Wario S. Trends of malaria morbidity and mortality from 2010 to 2017 in bale zone, ethiopia: Analysis of surveillance data. Infect Drug Resist. 2020;13:4379-87.

\section{Figures}

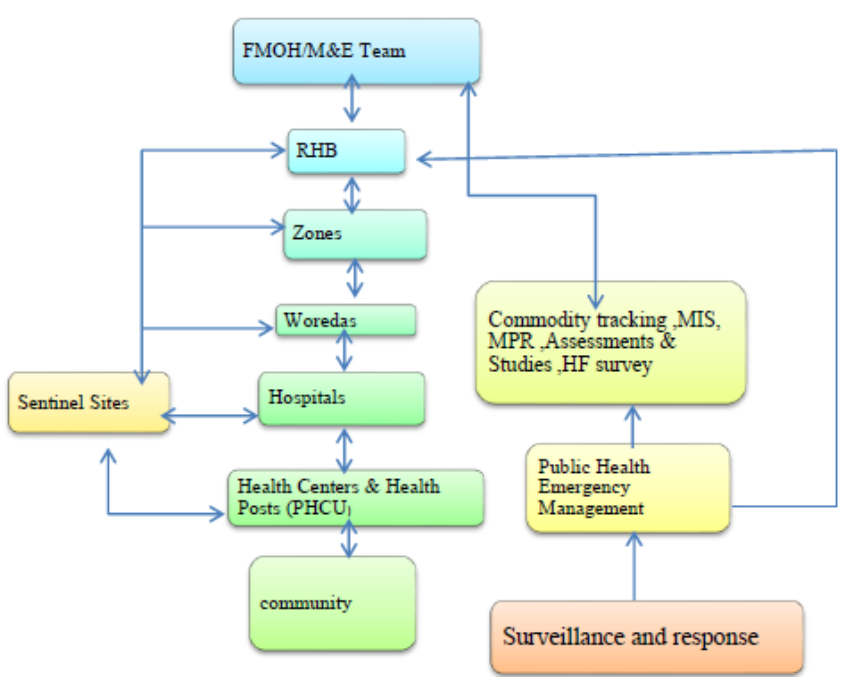

Page $10 / 14$ 
Figure 1

Overview of data source, flow and use in malaria M\&E system (adapted from National Malaria Program Monitoring and Evaluation Plan 2014-2020).

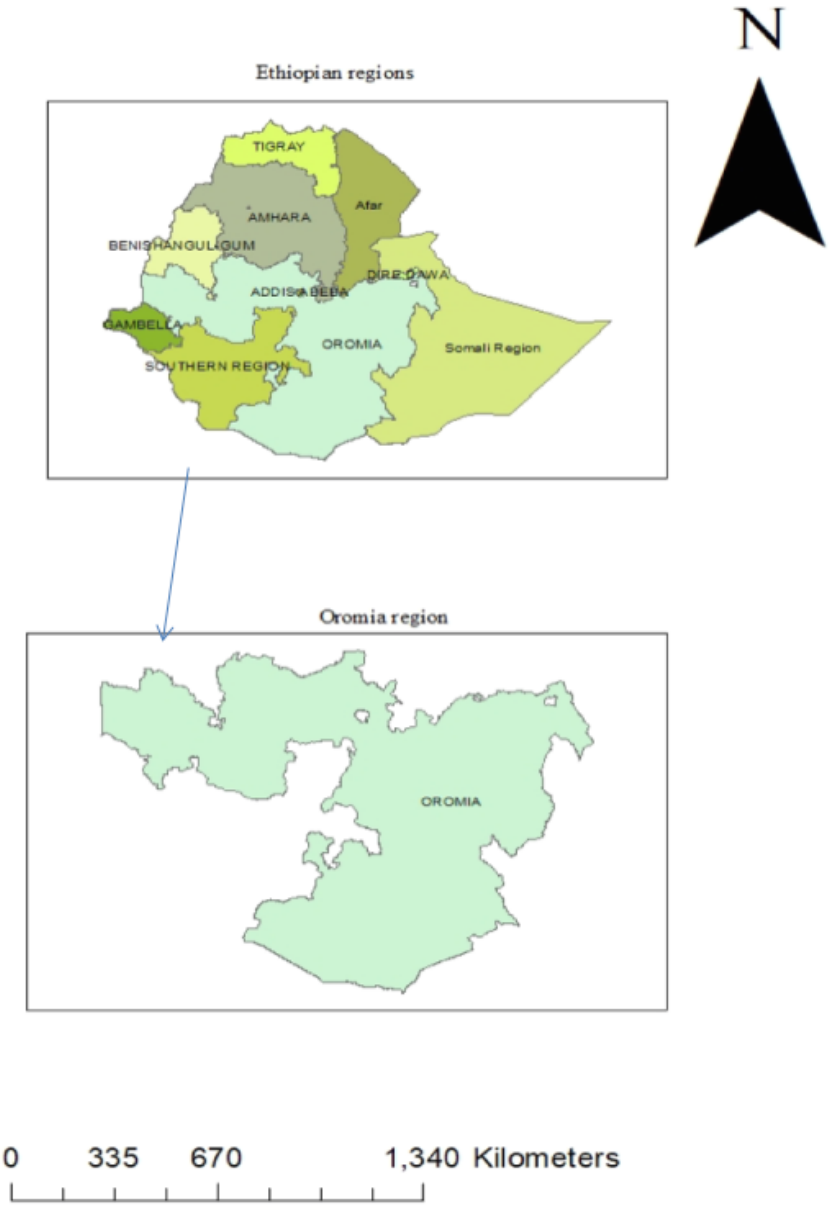

\section{Figure 2}

Map of Oromia Regional State, Ethiopia, May 2021.

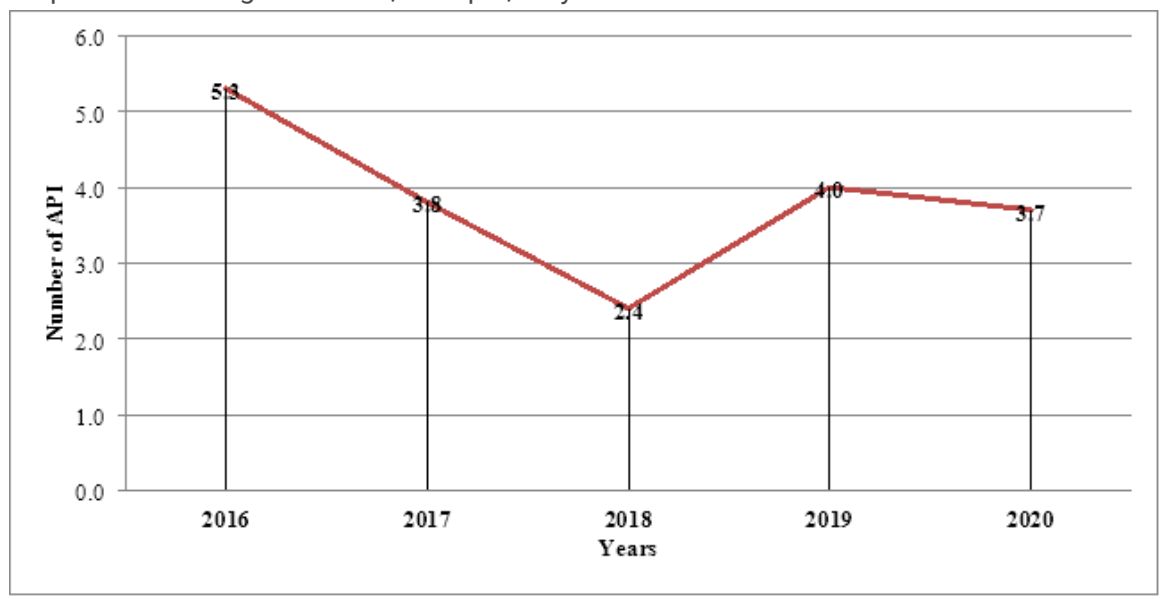

\section{Figure 3}

Trends of API from January 2016-December 2020, Oromia Regional State, Ethiopia. 


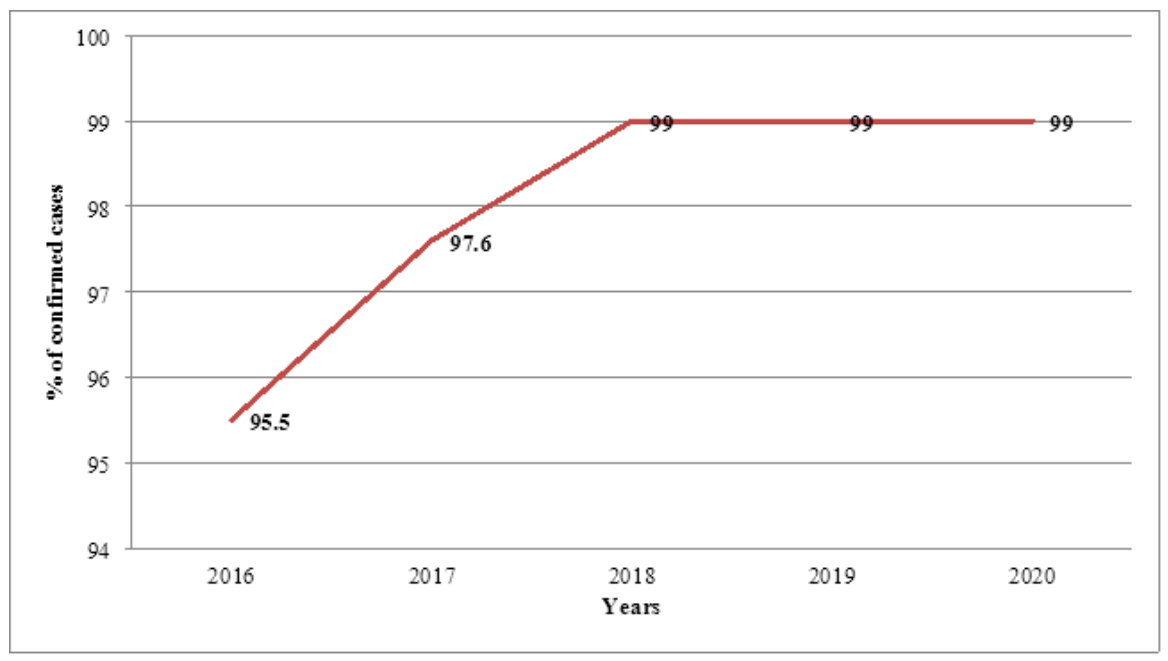

\section{Figure 4}

Trends of confirmed malaria cases in percentage from 2016-2020, Oromia regional state, Ethiopia.

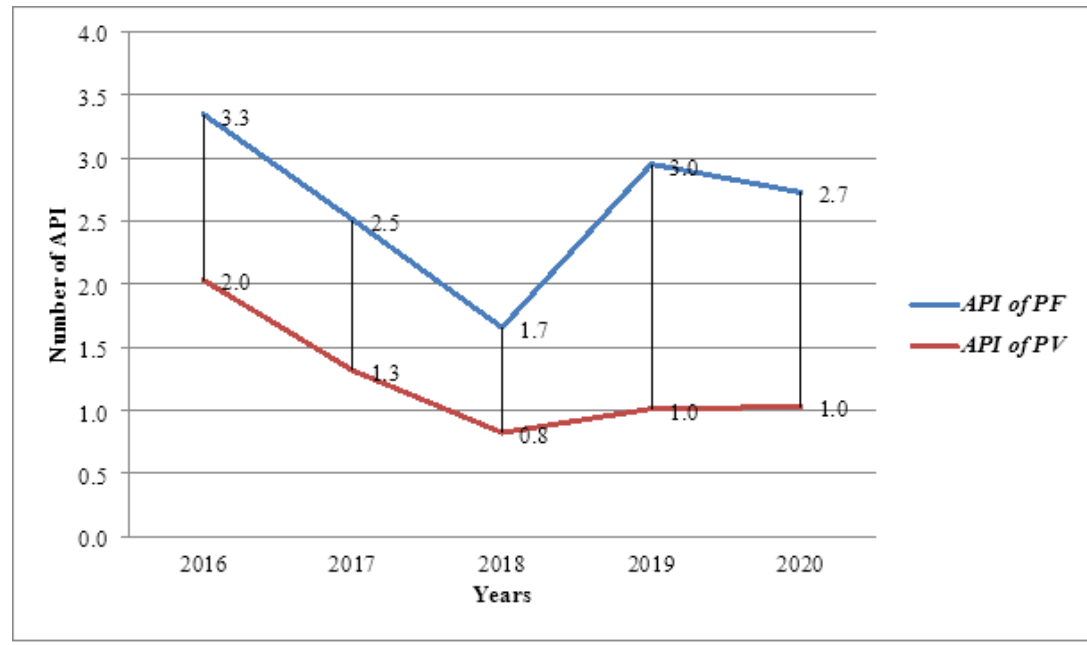

\section{Figure 5}

Trends of positive malaria cases with species from 2016-2020, Oromia, Ethiopia.

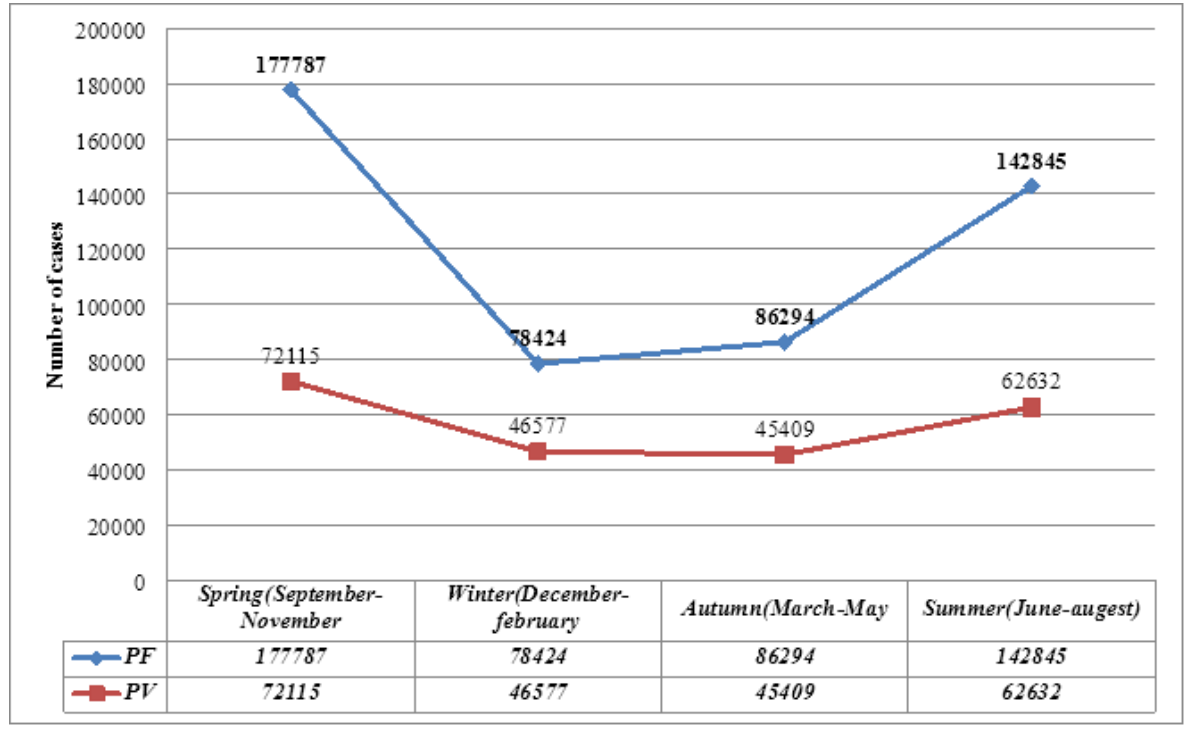

Figure 6

The distribution of PF and PV species in different seasons from 2016-2020, Oromia Regional State, Ethiopia.

Page $12 / 14$ 


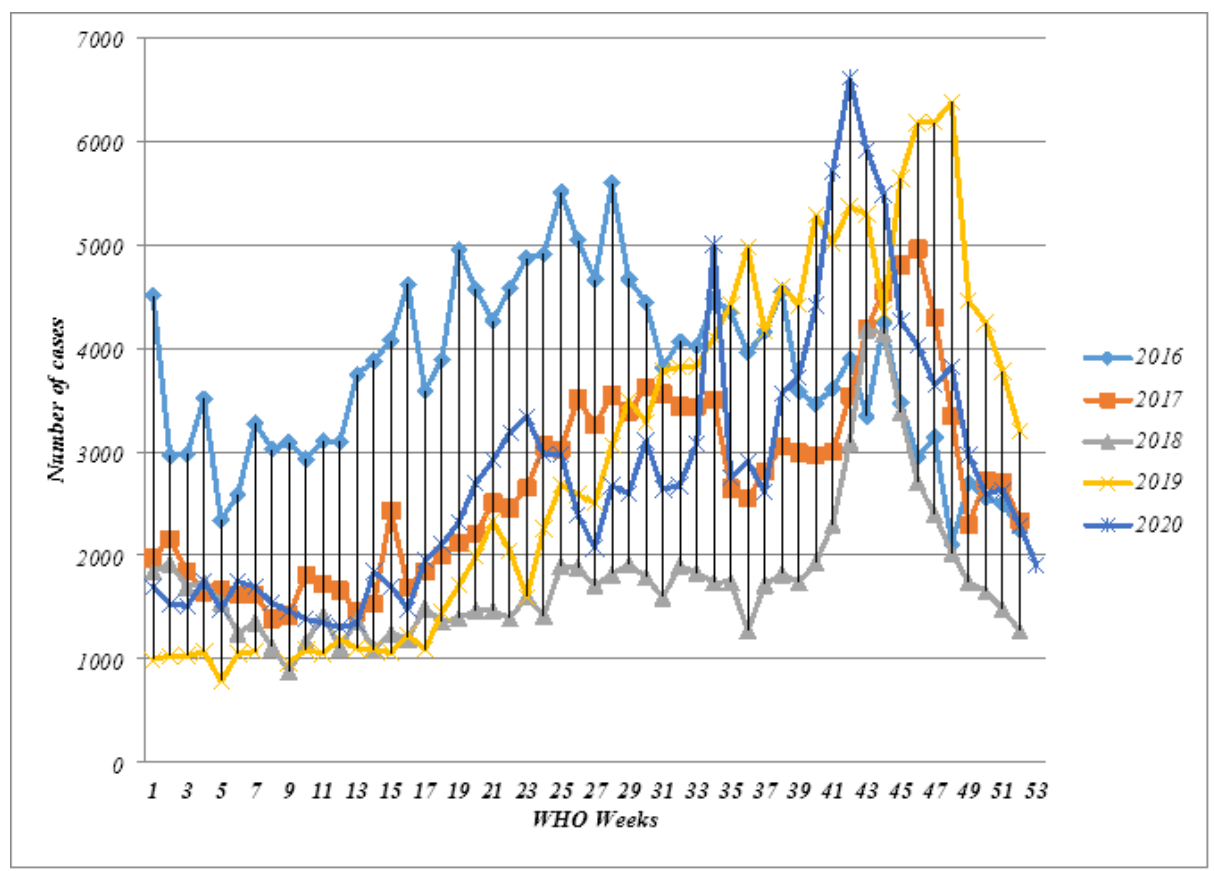

Figure 7

Trends of malaria in WHO Epidemic Weeks from January 2016-December 2020, Oromia Regional State, Ethiopia.

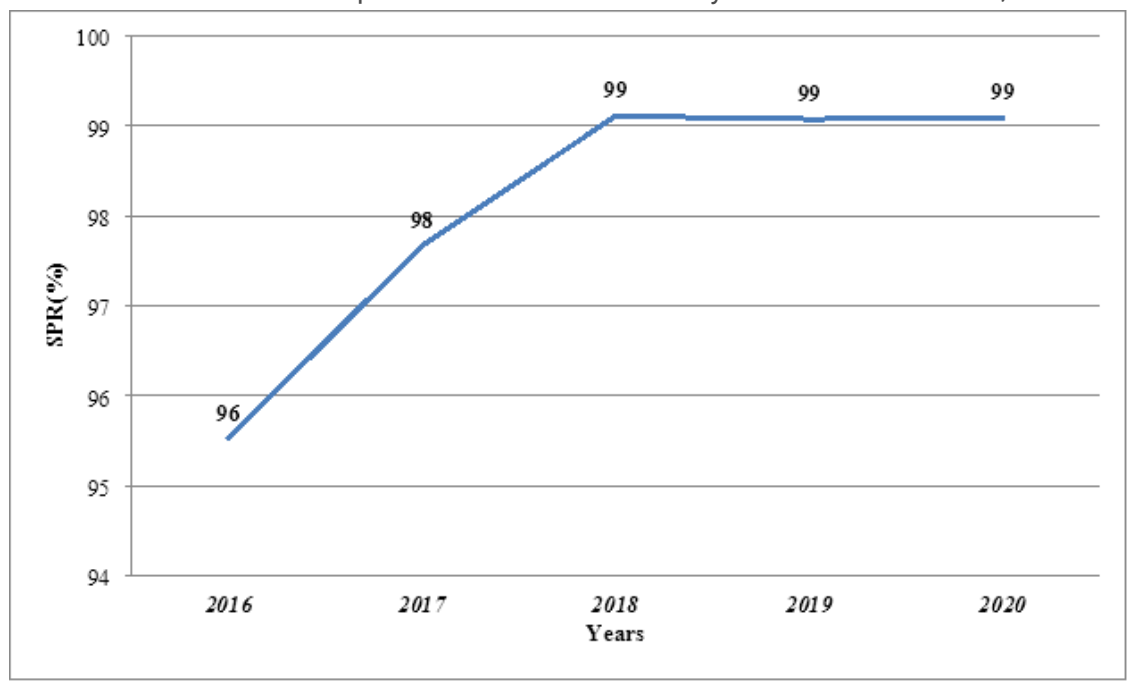

\section{Figure 8}

Trends of malaria SPR from January 2016-December 2020, Oromia Regional State, Ethiopia. 


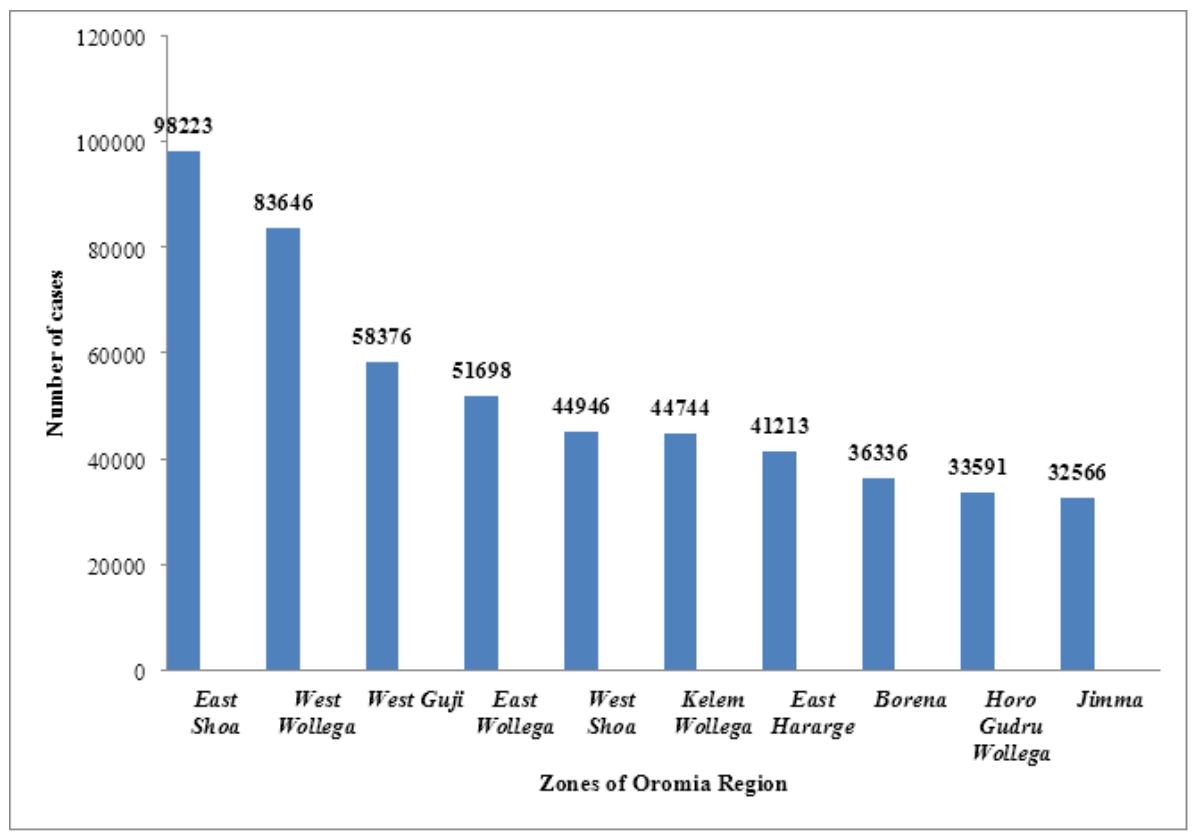

Figure 9

Top ten Zones of Oromia regional state by total confirmed malaria cases from January 2016-December 2020, Ethiopia.

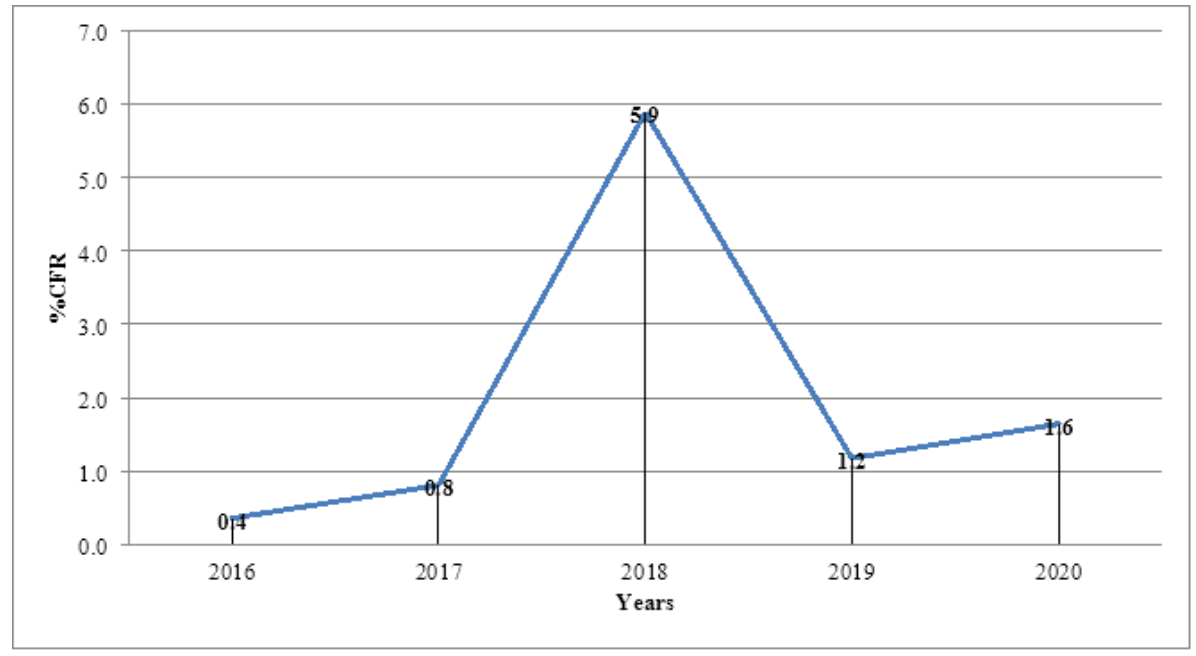

Figure 10

Trends of malaria CFR in Oromia regional state from 2016-2020, Ethiopia. 